\title{
(6) OPEN ACCESS \\ Prehospital determinants of successful resuscitation after traumatic and non-traumatic out-of-hospital cardiac arrest
}

\author{
Ed B G Barnard, ${ }^{\oplus 1,2}$ Daniel D Sandbach, ${ }^{1}$ Tracy L Nicholls, ${ }^{3}$ Alastair W Wilson, ${ }^{1}$ \\ Ari Ercole $e^{1,4}$
}

${ }^{1}$ Research and Clinical Innovation, East Anglian Air Ambulance, Norwich, UK ${ }^{2}$ Academic Department of Military Emergency Medicine, Royal Centre for Defence Medicine (Research and Clinical Innovation), Birmingham, UK ${ }^{3}$ Clinical Quality and Improvement, East of England Ambulance Service NHS Trust, Melbourn, UK

${ }^{4}$ Division of Anaesthesia, University of Cambridge, Cambridge, UK

Correspondence to Dr Ed B G Barnard, East Anglian Air Ambulance, Norwich, UK; edward.barnard@eaaa.org.uk

Received 1 October 2018 Revised 24 March 2019 Accepted 29 March 2019 Published Online First 19 April 2019

\section{Check for updates}

(c) Author(s) (or their employer(s)) 2019. Re-use permitted under CC BY-NC. No commercial re-use. See rights and permissions. Published by BMJ.

To cite: Barnard EBG, Sandbach DD, Nicholls TL, et al. Emerg Med J 2019:36:333-339.

\begin{abstract}
Background Out-of-hospital cardiac arrest (OHCA) is prevalent in the UK. Reported survival is lower than in countries with comparable healthcare systems; a better understanding of outcome determinants may identify areas for improvement.
\end{abstract}

Methods An analysis of 9109 OHCA attended in East of England between 1 January 2015 and 31 July 2017. Univariate descriptives and multivariable analysis were used to understand the determinants of survival for nontraumatic cardiac arrest (NTCA) and traumatic cardiac arrest (TCA). Two Utstein outcome variables were used: survival to hospital admission and hospital discharge. Results The incidence of OHCA was 55.1 per 100000 population/year. The overall survival to hospital admission was $27.6 \%$ (95\% Cl $26.7 \%$ to $28.6 \%$ ) and the overall survival to discharge was $7.9 \%(95 \% \mathrm{Cl} 7.3 \%$ to $8.5 \%$ ). Survival to hospital admission and survival to hospital discharge were both greater in the NTCA group compared with the TCA group: $27.9 \%$ vs $19.3 \%$ $p=0.001$, and $8.0 \%$ vs $3.8 \% p=0.012$ respectively. Determinants of NTCA and TCA survival were different, and varied according to the outcome examined. In NTCA, bystander cardiopulmonary resuscitation (CPR) was associated with survival at discharge but not at admission, and the likelihood of bystander CPR was dependent on geographical socioeconomic status. An air ambulance was associated with increased survival to both hospital admission and discharge in NTCA, but only with survival to admission in TCA

Conclusion NTCA and TCA are clinically distinct entities with different predictors for outcome-future OHCA reports should aim to separate arrest aetiologies. Determinants of survival to hospital admission and discharge differ in a way that likely reflects the determinants of neurological injury. Bystander CPR public engagement may be best focused in more deprived areas.

\section{INTRODUCTION}

Every year the ambulance services in England attempt resuscitation on approximately 30000 cases of out-of-hospital cardiac arrest (OHCA). ${ }^{1}$ Survival to hospital discharge in England is less than $10 \%$-lower than that of several other countries with developed emergency healthcare systems, ${ }^{2}$ indicating the need for improvement. Key to addressing this disparity is a better understanding of determinants of outcome.

\section{Key messages}

What is already known on this subject

- The ambulance services in England attempt resuscitation on 30000 patients with out-ofhospital cardiac arrest (OHCA) per year.

- OHCA survival to discharge in England is lower than that of countries with comparable healthcare systems.

- A better understanding of outcome determinants may identify specific targets for improvement of OHCA survival.

\section{What this study adds}

- Prehospital determinants of non-traumatic and traumatic cardiac arrest outcome are different; these conditions should be analysed and managed independently.

- The determinants of survival identified are likely to reflect the magnitude of neurological injury incurred during resuscitation.

- Social deprivation and bystander cardiopulmonary resuscitation rates are strongly collinear-presenting a target for public engagement in OHCA.

Demographic data on OHCA in England are routinely collected as part of the Out-of-Hospital Cardiac Arrest Outcome Project, ${ }^{3}$ providing a national, linkable source of epidemiological data. This project has reported a $25 \%$ survival to hospital admission, and a survival to discharge of $8 \%$. However, it has not modelled the associations between prehospital variables and survival outcomes, ${ }^{2}$ a process which could highlight opportunities for system improvements. Achieving a return of spontaneous circulation (ROSC) cannot be of benefit if the individual sustains a neurological injury from which they subsequently die; the prehospital phase plays an important role in this and deserves particular attention. Neurological outcome is critically determined by ambulance response time, ${ }^{4}$ and there are many prehospital interventions (initially, and during post-ROSC care) that may be important in determining outcome. These interventions potentially require specialist medical teams that are both expensive and limited in number. It is therefore important that they are properly evaluated and appropriately used. 
While research into management of OHCA is constrained by its very nature (unpredictable, resource limited, in an uncontrolled environment), ${ }^{6}$ the wide inclusion of all-cause OHCA in epidemiological studies potentially leads to a lack of clarity when reporting determinants of outcome. For example, traumatic cardiac arrest (TCA), predominantly caused by traumatic brain injury and haemorrhage, ${ }^{7}$ is a fundamentally different disease process to non-traumatic cardiac arrest (NTCA) that is largely of primary cardiac aetiology. ${ }^{8}$ Therefore, it would be expected that determinants of outcome are different for TCA and NTCA. However, most previous studies, including the Out-of-Hospital Cardiac Arrest Outcome Project, ${ }^{3}$ do not differentiate these conditions. There has been a substantial increase in reported survival from TCA since $2005 .{ }^{9}$ It is likely that a better understanding of this disease process, distinct from NTCA, has played a part in this improvement, but there remains a paucity of data comparing determinants of outcome from NTCA and TCA in the same patient cohort.

Our primary aim was to compare the differential determinants of survival to hospital admission and survival to hospital discharge for NTCA and TCA in a large regional cohort of OHCA.

\section{METHODS}

\section{Emergency medical service}

East of England is a geographic area of $20000 \mathrm{~km}^{2}$, containing a population of 6395000 (June 2016). ${ }^{10}$ The East of England Ambulance Service NHS Trust (EEAST) is the statutory emergency medical service for this area and receives over 1 million emergency calls per year to three Emergency Operations Centres. OHCA cases are assigned an immediate dispatch of a minimum of two double-staffed ambulances, including at least one paramedic. In addition, EEAST uses layperson community first responders, police and fire service coresponders and British Association for Immediate Care Scheme responders. All carry automated external defibrillators and are trained in basic life support as a minimum standard. These assets, as well as ambulance service rapid response vehicles, are used to meet the statutory 8 min response standard. ${ }^{11}$ Dispatch (by helicopter or car) of one of five physician-paramedic prehospital critical care teams in the East of England is at the discretion of the paramedic-led critical care desk at one of the EEAST Emergency Operations Centres.

\section{Data collection and variable definitions}

Data were obtained from EEAST for all cases of OHCA in which a resuscitation attempt was made between 1 January 2015 and 31 July 2017; EEAST only captures data in cases in which the ambulance service attempts resuscitation. ${ }^{12}$ These data are routinely collected, in an Utstein 2004 template, ${ }^{13}$ for submission to UK Government and the Out-of-Hospital Cardiac Arrest Outcome Project. Neurological outcome at discharge from hospital is not routinely recorded. The presence of an 'air ambulance' (prehospital critical care team, which may have been deployed by helicopter or rapid response vehicle) is also recorded.

Complete postcode data of the emergency call were only available for 2015 (from 2016 onwards data governance procedures precluded the storage of a complete postcode, reducing the accuracy of these data). From these, we obtained indices of social deprivation from the Ministry of Housing, Communities and Local Government data. ${ }^{14}$
The data were dichotomised into NTCA and TCA. NTCA is dominated by all-cause medical cardiac arrests, but also includes asphyxiation, drowning and electrocution. TCA is defined as cardiac arrest resulting from an external application of kinetic energy.

\section{Outcomes}

In keeping with the international consensus reporting guidelines for resuscitation (Utstein), we have reported two patient outcomes: 'survival to hospital admission' and 'survival to hospital discharge'. ${ }^{15}$ Survival to hospital in the absence of longer term survival is clearly not of benefit to the patient. However, in addition to the adherence to international data standards, the authors perceive substantial benefit to prehospital providers (who are not routinely informed of final patient outcome) in including the 'survival to hospital admission' outcome in this report.

\section{Statistical analyses}

Utstein 2004 variables (excluding neurological outcome), presence of an air ambulance medical team, postcode and indices of social deprivation were refactored into putative explanatory variables of interest after which $<<10 \%$ of the total was missing, except for social deprivation status where approximately $66 \%$ (ie, 2016 and 2017 patients) was not available. The response time was defined as emergency call origin to ambulance arrival at scene. Patients who had a cardiac arrest with the ambulance crew present (ie, those for which the original call was not a cardiac arrest but where the patient subsequently required cardiopulmonary resuscitation [CPR]) had the response time set to zero, rather than the response time of the initial call. Missing data were imputed under the assumption of missingness at random; predictive mean matching was used to generate 100 imputed data sets for each of the NTCA and TCA subsets. ${ }^{16}$

Multivariable logistic regression models were then constructed for the NTCA subgroup and pooled across imputations. Plausible covariates and interactions were introduced and the model successively simplified by eliminating predictors in such a way as to retain those that were significant for at least one outcome. To assess differences between the non-trauma (NTCA) and trauma (TCA) groups, this final model was then applied to the TCA group to assess its performance before further simplification, again to the point that only predictors with statistical significance for at least one outcome measure were retained. We assumed a significance level of 5\%.

Data manipulation and statistical analyses were performed using the $\mathrm{R}$ statistical programming language ( $\mathrm{R}$ Core Team [2018]; R: A language and environment for statistical computing [R Foundation for Statistical Computing, Vienna, Austria]). Statistical significance ( $\mathrm{p}$ values) is presented without correction for multiple comparison.

Data have been reported as number (percentage), number (percentage $[95 \% \mathrm{CI}]$ ) and median (IQR) as appropriate. Continuous data have been analysed with a Mann-Whitney U test, and categorical data have been analysed with a $\mathrm{X}^{2}$ test.

\section{RESULTS \\ Total population}

There were 9109 OHCA cases during the period studied. Overall, the median age was 73 years (60-83), and 5721 $(62.8 \%)$ were male. The incidence of OHCA was 55.1 per 100000 population/year. The survival to hospital admission was $27.6 \%$ (95\% CI 26.7 to 28.6 ), and the survival to hospital 


\begin{tabular}{|c|c|c|c|}
\hline Variable & NTCA & TCA & $P$ value \\
\hline Total, n (\%) & 8805 (96.7) & $304(3.3)$ & \\
\hline Median age, years (IQR) & $74(61-83)$ & $43(30-61)$ & $<0.001 * * *$ \\
\hline Gender, male (\%) & 62.5 & 77.0 & $<0.001^{* * *}$ \\
\hline Witnessed arrest, n (\%) & $4950(56.4)$ & $103(34.0)$ & $<0.001$ *** \\
\hline Not recorded, $\mathrm{n}$ & 24 & 1 & \\
\hline Bystander CPR, n (\%) & 4719 (54.6) & $156(52.2)$ & $0.40 \mathrm{NS}$ \\
\hline Not recorded, $\mathrm{n}$ & 166 & 5 & \\
\hline \multicolumn{4}{|l|}{ First monitored rhythm } \\
\hline Asystole, $n(\%)$ & $4689(56.0)$ & $204(70.6)$ & $<0.001 * * *$ \\
\hline PEA, n (\%) & $1862(22.3)$ & $69(23.9)$ & $0.52 \mathrm{NS}$ \\
\hline$V F, n(\%)$ & $1697(20.3)$ & $14(4.8)$ & $<0.001^{* * *}$ \\
\hline $\mathrm{VT}, \mathrm{n}(\%)$ & $87(1.0)$ & $1(0.3)$ & $0.25 \mathrm{NS}$ \\
\hline Other, $\mathrm{n}(\%)$ & $32(0.4)$ & $1(0.3)$ & $0.92 \mathrm{NS}$ \\
\hline Not recorded, $\mathrm{n}$ & 438 & 15 & \\
\hline \multicolumn{4}{|l|}{ Survival } \\
\hline Admission, $\mathrm{n}(\%, 95 \% \mathrm{Cl})$ & $\begin{array}{l}2423(27.9 \\
95 \% \mathrm{Cl} 27.0 \text { to } 28.9)\end{array}$ & $\begin{array}{l}58(19.3 \\
95 \% \mathrm{Cl} 15.3 \text { to } 24.2)\end{array}$ & $<0.001$ *** \\
\hline Discharge, $\mathrm{n}(\%, 95 \% \mathrm{Cl})$ & $\begin{array}{l}623(8.0, \\
95 \% \mathrm{Cl} 7.4 \text { to } 8.7)\end{array}$ & $\begin{array}{l}10(3.8 \\
95 \% \mathrm{Cl} 2.1 \text { to } 6.8)\end{array}$ & $0.012^{*}$ \\
\hline
\end{tabular}

CPR, cardiopulmonary resuscitation; NS, not significant; NTCA, non-traumatic cardiac arrest; PEA , pulseless electrical activity; TCA, traumatic cardiac arrest; VF, ventricular fibrillation; VT, ventricular tachycardia.

${ }^{*}<0.05$

$* * *<0.001$

discharge was $7.9 \%$ (95\% CI 7.3 to 8.5$)$. The median response time (defined as emergency call origin to ambulance arrival at scene) was $6.3(4.0-10.0) \mathrm{min} ; 67.1 \%$ were within the statutory 8 min standard. ${ }^{11}$

\section{Comparison of NTCA and TCA cohorts}

The majority $(n=8805)$ of patients had suffered NTCA (table 1$)$. The incidence of NTCA per 100000 population/year was 53.3 (figure 1) (left panel). Three hundred and four patients were reported as TCA (table 1). The incidence of TCA per 100000 population/year was 1.8 (figure 1) (right panel).

The NTCA cohort was significantly older, contained a higher proportion of female patients and was more likely to have had a witnessed arrest compared with the TCA cohort; rates of bystander CPR were comparable (table 1). The most prevalent initial cardiac rhythm in both groups was asystole. However, the NTCA cohort contained a significantly smaller proportion of asystole and a significantly larger proportion of ventricular fibrillation (VF) compared with the TCA cohort (table 1). Survival to hospital admission and survival to hospital discharge were both significantly higher in the NTCA group compared with the TCA group (table 1 and figure 2 ).

\section{Multivariable analysis}

Non-traumatic cardiac arrest

The final logistic regression models for NTCA survival are summarised in table 2 .
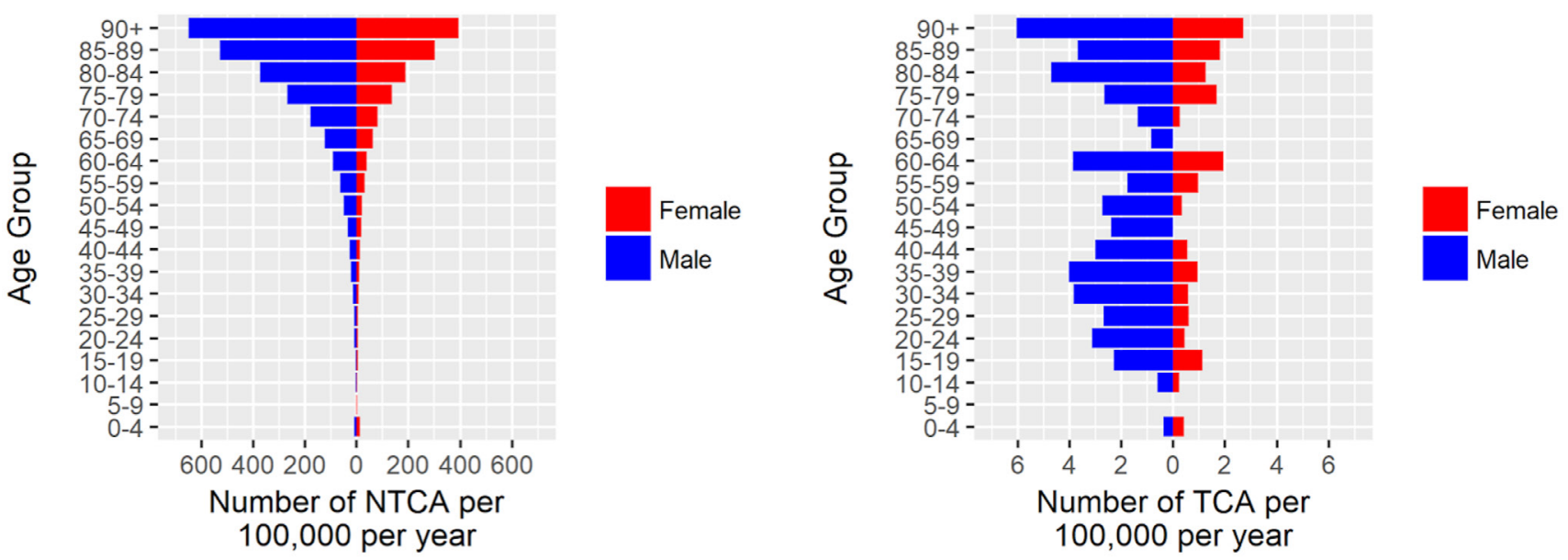

Figure 1 (Left panel) Incidence of non-traumatic cardiac arrest (NTCA) per 100000 population by age group and sex ( $n=8557)$ : age or sex data were not recorded in $n=248$ cases. (Right panel) Traumatic cardiac arrest (TCA) per 100000 population by age group and sex ( $n=245$ ): age or sex data were not recorded in $n=59$ cases. 


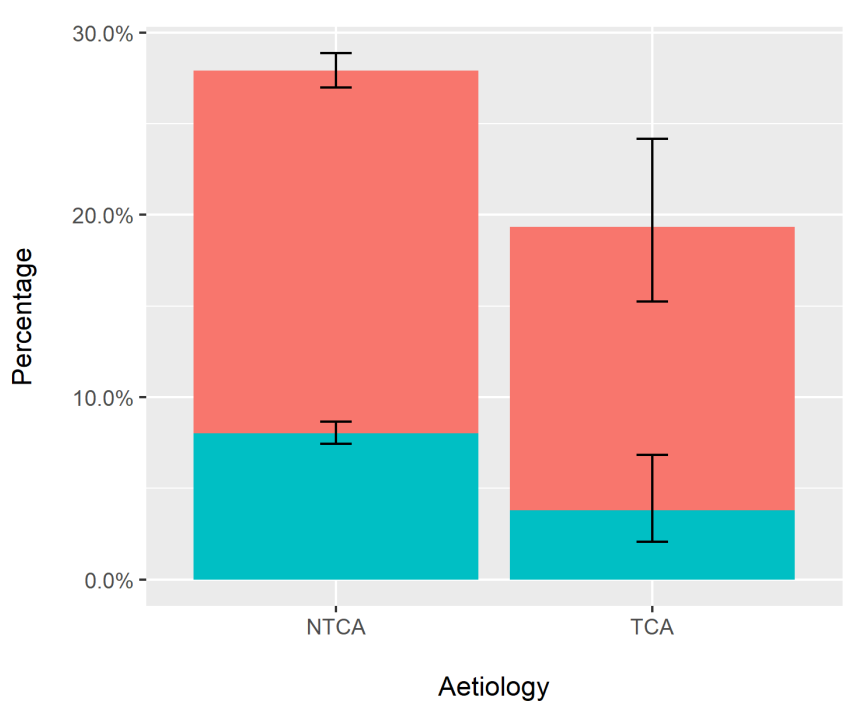

Survival to hospital admission

Survival to hospital discharge

Figure 2 Survival to hospital admission and survival to hospital discharge for non-traumatic cardiac arrest (NTCA) and traumatic cardiac arrest (TCA) cohorts, with $95 \%$ Cls.

Terms up to quadratic for age were included as age was found to have a strong non-linear relationship with outcome. Index of multiple deprivation and bystander CPR were found to be strongly collinear, and therefore only the latter was retained on mechanistic grounds. Whether the patient had been defibrillated prior to ambulance arrival $(n=141)$ was not statistically significant and eliminated. We found no evidence of statistically significant interactions between response time and either a shockable initial rhythm or whether the arrest was witnessed. Furthermore, we could find no evidence that cardiac arrests occurring at weekends carried a statistically different outcome, and this variable was eliminated.

Age, male sex, response time and the documented administration of epinephrine were all associated with adverse hospital arrival outcome, whereas the presence of a shockable initial rhythm, the attendance of an air ambulance and successful intubation were positively associated. The pattern is different for survival to hospital discharge: in this case, male sex was now found to carry a survival advantage and successful intubation to be associated with mortality. However, the presence of an air ambulance remained significantly associated with survival to hospital discharge. The documented presence of bystander CPR only entered into the model via its interaction with response time, but this was only significantly associated with survival to discharge, not admission.

The results presented, using multiple imputation, were consistent with a total case analysis, but for clarity only the final, most robust model has been included; for completeness, the summary data (before multiple imputation) for the NTCA cohort are presented in table 3 .

\section{Traumatic cardiac arrest}

The results of applying the final NTCA multivariable model to the TCA cohort are shown in table 4.

For the hospital admission outcome, only the presence of an air ambulance was associated with survival, but this did not translate to improved survival to hospital discharge, and there was a negative association with survival to hospital for witnessed TCA (table 4). For the survival to hospital discharge endpoint, only an initial shockable rhythm was significant. The median (IQR) age of patients with TCA with and without a shockable rhythm was 63 (30-82) years and 43 (30-60) years, respectively, $\mathrm{p}=0.025$. Summary data (before multiple imputation) are presented in table 5 .

\section{DISCUSSION}

Our study has demonstrated significant differences in the epidemiology, presentation and predictors of outcome between NTCA and TCA. Furthermore, we have identified differences in the prehospital determinants of survival to hospital admission and survival to hospital discharge.

The overall incidence of OHCA in the East of England during the study period is comparable to England in 2014: 55.1 and 53.2 per 100000 population/year, respectively. ${ }^{2}$ The overall survival to hospital arrival was significantly higher than national data $(27.6 \%$ vs $25.8 \%, \mathrm{p}<0.001)$, but the survival to discharge was the same (both $7.9 \%$ ). ${ }^{2}$ This suggests that even though a higher proportion of patients are initially 'successfully' resuscitated in the East of England, this does not translate to greater survival

Table 2 Results of multivariable logistic regression on imputed data set for NTCA survival to hospital admission or survival to receiving hospital discharge outcomes

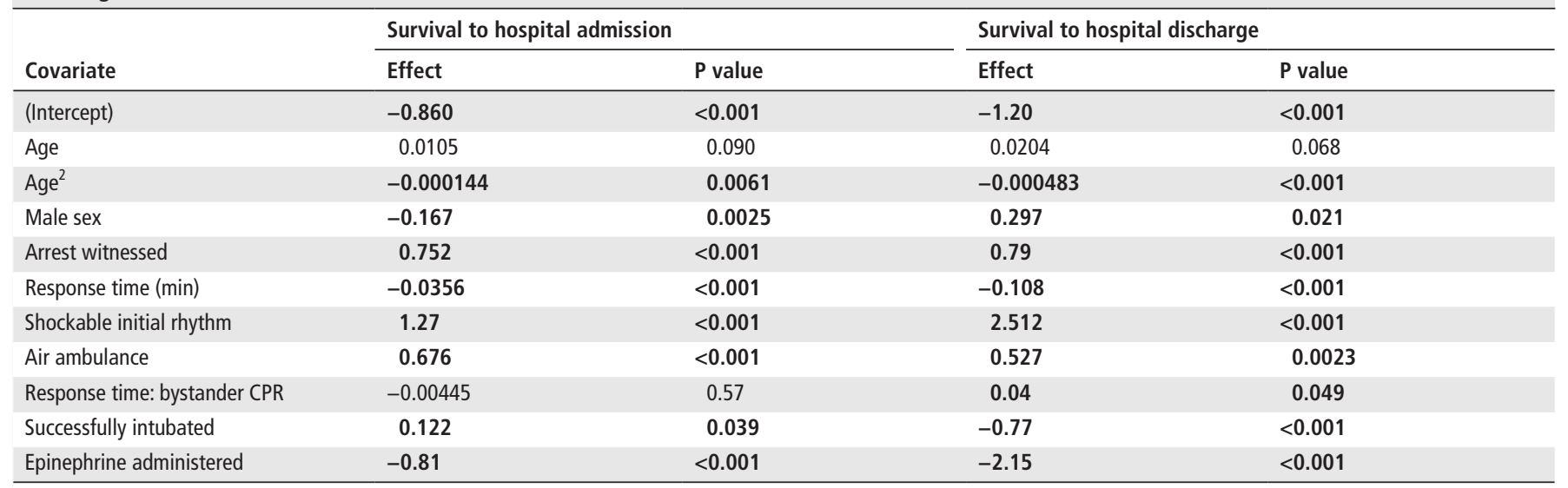

Models were simplified by sequential elimination of terms and interactions that were not significant for at least one of the two outcomes. Significant covariate estimates are denoted in bold assuming a significance level of $5 \%$ and estimates are log odds.

CPR, cardiopulmonary resuscitation; NTCA, non-traumatic cardiac arrest. 
Table 3 Summary statistics (before multiple imputation) for significant predictors in the NTCA model. Percentages are of the total $\mathrm{n}$ of patients with NTCA

\begin{tabular}{lcccc}
\hline & $\begin{array}{l}\text { Survived to hospital } \\
\text { admission }\end{array}$ & $\begin{array}{l}\text { Did not survive to hospital } \\
\text { admission }\end{array}$ & $\begin{array}{l}\text { Survived to hospital } \\
\text { discharge }\end{array}$ & $\begin{array}{l}\text { Survived to admission but } \\
\text { not discharge }\end{array}$ \\
\hline Median age, years (IQR) & $71(58-81)$ & $75(62-84)$ & $63(50-73)$ & $74(62-83)$ \\
\hline Male, $\mathrm{n}(\%)$ & $1551(17.6)$ & $3939(44.7)$ & $411(4.7)$ & $663(7.5)$ \\
\hline Female, $\mathrm{n}(\%)$ & $868(9.9)$ & $2422(27.5)$ & $119(1.4)$ & $418(4.7)$ \\
\hline Witnessed arrest, $\mathrm{n}(\%)$ & $1752(19.9)$ & $3198(36.3)$ & $440(5.0)$ & $763(8.7)$ \\
\hline Unwitnessed arrest, $\mathrm{n}(\%)$ & $666(7.6)$ & $3165(35.9)$ & $90(1.0)$ & $319(3.6)$ \\
\hline Median response time, min (IQR) & $5.0(3.0-8.0)$ & $6.0(3.9-9.0)$ & $4.4(1.0-7.0)$ & $6.0(3.1-8.0)$ \\
\hline Shockable rhythm, $\mathrm{n}(\%)$ & $911(10.3)$ & $775(8.8)$ & $373(4.2)$ & $282(3.2)$ \\
\hline Non-shockable rhythm, $\mathrm{n}(\%)$ & $1319(15.0)$ & $5362(60.9)$ & $98(1.1)$ & $737(8.4)$ \\
\hline Successfully intubated, $\mathrm{n}(\%)$ & $916(10.4)$ & $2228(25.3)$ & $121(1.4)$ & $489(5.6)$ \\
\hline Not intubated, $\mathrm{n}(\%)$ & $1326(15.0)$ & $3683(41.8)$ & $369(4.2)$ & $558(6.3)$ \\
\hline Epinephrine, $\mathrm{n}(\%)$ & $1689(19.2)$ & $5462(62.0)$ & $187(2.1)$ & $895(10.2)$ \\
\hline No epinephrine, $\mathrm{n}(\%)$ & $735(8.3)$ & $915(10.4)$ & $343(3.9)$ & $188(2.1)$ \\
\hline
\end{tabular}

NTCA, non-traumatic cardiac arrest.

to hospital discharge. Our figure of $3.8 \%$ survival to discharge following TCA is lower than the $7.5 \%$ recently reported in England and Wales (which excluded patients pronounced life extinct prehospital) ${ }^{7}$; our figure is therefore likely to be a more accurate total population estimate. ${ }^{17}$

\section{Comparison of NTCA and TCA}

Comparison of NTCA and TCA cohorts demonstrated that patients with TCA were younger and more likely to be male. This is not a surprising result, and similar findings have recently been reported. ${ }^{18}$ However, we are unable to explain why TCA was less likely to be witnessed than NTCA; it might be that a proportion of patients with NTCA were unwell and therefore sought assistance prior to arrest, whereas TCA had a more sudden onset.

The only prehospital variable associated with increased survival to hospital discharge in both NTCA and TCA cohorts was a 'shockable initial rhythm'. An initial shockable rhythm is well known to increase the chance of survival in NTCA, but this finding is puzzling following TCA, in which shockable rhythms are rare ${ }^{19}$ It is possible that this group comprises patients in whom the 'trauma' was preceded by a primary cardiac OHCA, which would most likely be a ventricular dysrhythmia (VF/ventricular tachycardia), and as such would have a 'more-survivable' underlying aetiology. The TCA group with a shockable rhythm was significantly older than those without, and emphasises the need for caution when applying bespoke TCA management protocols

Table 4 Results of multivariable logistic regression on imputed data set for TCA survival to hospital admission or survival to receiving hospital discharge outcomes

\begin{tabular}{llllll}
\hline & \multicolumn{2}{l}{$\begin{array}{l}\text { Survival to hospital } \\
\text { admission }\end{array}$} & & \multicolumn{2}{l}{$\begin{array}{l}\text { Survival to hospital } \\
\text { discharge }\end{array}$} \\
\cline { 2 - 3 } \cline { 5 - 6 } Covariate & Effect & P value & & Effect & P value \\
\hline (Intercept) & -0.970 & 0.0014 & & -2.89 & $<0.001$ \\
Arrest witnessed & -0.76 & 0.035 & & -0.784 & 0.26 \\
Response time (min) & -0.072 & 0.057 & & -0.00944 & 0.89 \\
Shockable initial rhythm & 0.777 & 0.22 & & 2.49 & 0.0030 \\
Air ambulance & 0.952 & 0.012 & & 0.180 & 0.83 \\
\hline
\end{tabular}

Models were simplified by sequential elimination of terms and interactions that were not significant for at least one of the two outcomes. Significant covariate estimates are denoted in bold assuming a significance level of $5 \%$ and estimates are log odds.

TCA, traumatic cardiac arrest. to older patients. Therefore, the only common prehospital determinant of survival to discharge between NTCA and TCA is potentially due to misdiagnosis, and together with the differences observed in epidemiology and presenting cardiac rhythm, provides evidence that these are clinically distinct entities that should be analysed separately and managed differently.

\section{Comparison of survival outcomes}

It is not possible for a patient to survive to hospital discharge without an ROSC. Conversely, survival to hospital admission cannot be of benefit, and is potentially harmful, if the patient does not survive to hospital discharge. Determinants of survival at the two time points were found to be different in both NTCA and TCA cohorts. In NTCA, male sex conferred a survival disadvantage at hospital admission but a survival advantage at discharge. This is presumably owing to a difference in the aetiologies between male and female OHCA. Documented bystander CPR reduced the negative effect of longer response times; this is consistent with previous findings that bystander CPR does not improve neurological outcome in short response times. ${ }^{20}$ That this conferred a survival benefit at hospital discharge but not at admission has not to our knowledge been previously described. This is likely to reflect a greater degree of neurological injury (probably the dominant cause of ultimate death) in patients with a period without CPR, whereas ROSC is still obtained in such patients due to the relative tolerance of the heart to ischaemia; this matters less when response times are short.

Successful prehospital intubation was positively associated with survival to hospital admission, but negatively associated with survival to discharge. This is likely to reflect the effectiveness of resuscitation to achieve an ROSC even after a period of arrest that is neurologically devastating, and is in keeping the findings of the recent Effect of a Strategy of a Supraglottic Airway Device vs Tracheal Intubation During Out-of-Hospital Cardiac Arrest on Functional Outcome (AIRWAYS-2) trial. ${ }^{21}$ This trial demonstrated no difference in neurologically intact survival between supraglottic airway (SGA) use and intubation, but also included $n=1707$ (18.4\%) patients who did not receive an advanced airway (owing to a short-duration arrest), $21.1 \%$ of these patients had a good outcome compared with 3.3\% of those who received an advanced airway. ${ }^{21}$ In addition, there was a higher proportion of patients in the intubation arm who did not receive an advanced airway compared with those randomised to 
Table 5 Summary statistics (before multiple imputation) for significant predictors in the TCA model. Percentages are of the total $\mathrm{n}$ of patients with TCA

\begin{tabular}{llccc}
\hline & $\begin{array}{l}\text { Survived to hospital } \\
\text { admission }\end{array}$ & $\begin{array}{l}\text { Did not survive to hospital } \\
\text { admission }\end{array}$ & $\begin{array}{l}\text { Survived to hospital } \\
\text { discharge }\end{array}$ & $\begin{array}{l}\text { Survived to admission but } \\
\text { not discharge }\end{array}$ \\
\hline Witnessed arrest, $\mathrm{n}(\%)$ & $13(4.3)$ & $90(30.0)$ & $2(0.7)$ & $5(1.6)$ \\
\hline Unwitnessed arrest, $\mathrm{n}(\%)$ & $44(14.5)$ & $156(51.3)$ & $6(2.0)$ & $19(6.3)$ \\
\hline Median response time, min (IQR) & $5.0(3.0-7.8)$ & $6.0(4.0-9.7)$ & $4.0(3.5-7.3)$ & $5.0(2.5-6.6)$ \\
\hline Shockable rhythm, $\mathrm{n}(\%)$ & $4(1.3)$ & $11(3.6)$ & $3(1.0)$ & $0(0)$ \\
\hline Non-shockable rhythm, $\mathrm{n}(\%)$ & $50(16.4)$ & $224(73.7)$ & $4(1.3)$ & $25(8.2)$ \\
\hline Air ambulance, $\mathrm{n}(\%)$ & $14(4.6)$ & $29(9.5)$ & $1(0.3)$ & $8(2.6)$ \\
\hline No air ambulance, $\mathrm{n}(\%)$ & $44(14.5)$ & $217(71.4)$ & $7(2.3)$ & $17(5.6)$ \\
\hline
\end{tabular}

TCA, traumatic cardiac arrest.

the SGA arm $(985 / 4410,22.3 \%$ and $722 / 4886,14.8 \%$ respectively), indicating that patients with OHCA who are intubated are likely to have had a longer duration arrest, and by inference a worse outcome.

A negative association between the administration of prehospital epinephrine and outcome has been previously reported. ${ }^{22}$ The recent randomised trial Pre-hospital Assessment of the Role of Adrenaline: Measuring the Effectiveness of Drug administration In Cardiac arrest (PARAMEDIC-2) demonstrated a 30-day survival advantage for epinephrine versus placebo, but no difference in neurological intact survival. ${ }^{23}$ This suggests that while epinephrine administration may increase survival this does not translate to meaningful survival in OHCA. This trial excluded patients who had an ROSC during initial resuscitation (before epinephrine was indicated), and are therefore a cohort of longer duration arrests that would be expected to have a worse outcome. Our data also included patients who had an early ROSC, in whom epinephrine was not administered, which might explain our findings that epinephrine administration was associated with worse outcomes (compounded by the length of arrest).

The presence of an air ambulance was strongly associated with improved survival at both time points in NTCA and at admission in TCA. It would be tempting to attribute this to the critical care skills of air ambulance providers, and previous literature has suggested this. ${ }^{24}$ However, in the East of England this is also likely to represent effective triage of patients who are more likely to survive. In particular, we cannot determine how many of the patients attended by an air ambulance had already obtained ROSC, with the critical care team instead being tasked to assist with post-ROSC care.

It is interesting that we were not able to demonstrate a statistically significant effect of defibrillation prior to arrival of EEAST, which we take to be a measure of the effectiveness of public access defibrillators corrected for the other factors that we considered. However, only a small number of patients $(n=141)$ were defibrillated prior to EEAST arrival, introducing the chance of a type 2 error.

The Index of Multiple Deprivation was removed from the multivariable model as it was found to strongly covary with documented bystander CPR. Univariable analysis found a strong association between receiving bystander CPR and Index of Multiple Deprivation with patients more likely to receive bystander CPR in less deprived postcodes $(p=0.002)$. We cannot draw conclusions on whether this is a result of social, cultural or educational factors, or whether this is the result of geographic population sparsity, but our results do suggest a potentially high-impact target area for policy efforts to improve public engagement with bystander CPR.
For patients suffering from TCA, the multivariable analysis results were very different from NTCA. There was only weak evidence $(p=0.057)$ that shorter response times were associated with increased survival at hospital arrival, and no evidence for increased survival at discharge. For survival to hospital discharge, an initial shockable rhythm was the only significant covariate.

Our approach using regional data has the advantage of limiting variations in care provision and geographical influences. This approach may offer the possibility of exploiting regional differences in a comparative effectiveness research model to further understand the determinants of outcome. Our work motivates a national, or indeed international, effort towards provider profiling regions to look for important covariates.

\section{Limitations}

Like any retrospective observational analysis, it is difficult to assign causality and our results are limited by any inherent errors in the data. However, it is reassuring that the missingness was low. We were unable to include in-hospital management variables in our model, these may have potentially confounded the survival to discharge outcome.

'Survival to discharge' from the receiving hospital may include patients who leave the receiving hospital not because they ultimately survive but because they are transferred to specialist centres for prognostication and perhaps subsequently go on to die. Unfortunately, we have no way of knowing this from our data. Furthermore, survival to hospital discharge data was obtained by follow-up and therefore may be missing not at random.

\section{CONCLUSIONS}

NTCA and TCA are clinically distinct entities with different predictors for outcome-future OHCA reports should aim to separate arrest aetiologies. Determinants of survival to hospital admission and discharge differ in a way that likely reflects the determinants of neurological injury. Bystander CPR public engagement may be best focused in more deprived areas.

Acknowledgements We acknowledge the assistance of the Audit and Research team at East of England Ambulance Service NHS Trust in compiling the original data, and the assistance of Mr Andrew Downes, Dr Tobias Gauss and Dr James Price (all East Anglian Air Ambulance) in the development of the AngliaOHCA project.

Contributors The study was conceived by EB, AE and AW. Data were supplied by TLN. Data analyses were undertaken by AE and DDS, with input from EB, AW and TLN. The manuscript was drafted by EB, DDS and AE, with critical review by TLN and AW. All authors have reviewed and agreed to the final manuscript.

Funding The authors have not declared a specific grant for this research from any funding agency in the public, commercial or not-for-profit sectors. 
Competing interests None declared.

Patient consent for publication Not required.

Ethics approval Institutional approval was granted by EEAST as a service evaluation (EEAST/1819/0019) in order to access, analyse and publish these anonymised data, and therefore specific ethical review was waived.

Provenance and peer review Not commissioned; externally peer reviewed.

Open access This is an open access article distributed in accordance with the Creative Commons Attribution Non Commercial (CC BY-NC 4.0) license, which permits others to distribute, remix, adapt, build upon this work non-commercially, and license their derivative works on different terms, provided the original work is properly cited, appropriate credit is given, any changes made indicated, and the use is non-commercial. See: http://creativecommons.org/licenses/by-nc/4.0/.

\section{REFERENCES}

1 Resuscitation Council (UK). NHS England, British Heart Foundation. Consensus paper on out-of-hospital cardiac arrest in England. Resuscitation Council 2014.

2 Hawkes C, Booth S, Ji C, et al. Epidemiology and outcomes from out-of-hospital cardiac arrests in England. Resuscitation 2017:110:133-40.

3 Rajagopal S, Booth SJ, Brown TP, et al. Data quality and 30-day survival for out-ofhospital cardiac arrest in the UK out-of-hospital cardiac arrest registry: a data linkage study. BMJ Open 2017;7:e017784.

4 Leis CC, Hernández CC, Blanco MJ, et al. Traumatic cardiac arrest: should advanced life support be initiated? J Trauma Acute Care Surg 2013;74:634-8.

5 von Vopelius-Feldt J, Powell J, Morris R, et al. Prehospital critical care for out-ofhospital cardiac arrest: An observational study examining survival and a stakeholderfocused cost analysis. BMC Emerg Med 2016;16:47.

6 von Vopelius-Feldt J, Brandling J, Benger J. Systematic review of the effectiveness of prehospital critical care following out-of-hospital cardiac arrest. Resuscitation 2017:114:40-6.

7 Barnard E, Yates D, Edwards A, et al. Epidemiology and aetiology of traumatic cardiac arrest in England and Wales - A retrospective database analysis. Resuscitation 2017:110:90-4

8 Hayashi M, Shimizu W, Albert CM. The spectrum of epidemiology underlying sudden cardiac death. Circ Res 2015;116:1887-906.

9 Lockey DJ, Lyon RM, Davies GE. Development of a simple algorithm to guide the effective management of traumatic cardiac arrest. Resuscitation 2013;84:738-42.

10 Office for National Statistics. Revised population estimates for England and Wales:

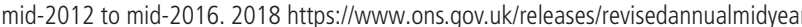
populationestimates2012to2016 (Accessed 1st August 2018).

11 Department of Health and Social Care. NHS Constitution for England: resources, 2015 https://www.gov.uk/government/collections/nhs-constitution-for-englandresources (Accessed 1st August 2018).
12 Class Publishing. Joint Royal Colleges Ambulance Liaison Committee, Association of Ambulance Chief Executives. UK ambulance services clinical practice guidelines 2016. Bridgewater: Class Publishing, 2016.

13 Jacobs I, Nadkarni V, Bahr J, et al. Cardiac arrest and cardiopulmonary resuscitation outcome reports: update and simplification of the Utstein templates for resuscitation registries. A statement for healthcare professionals from a task force of the international liaison committee on resuscitation (American Heart Association, European Resuscitation Council, Australian Resuscitation Council, New Zealand Resuscitation council, heart and stroke foundation of Canada, InterAmerican Heart Foundation, Resuscitation Council of Southern Africa). Resuscitation 2004;63:233-49.

14 Ministry of Housing, Communities \& Local Government. English indices of deprivation 2015. 2015 https://www.gov.uk/government/statistics/english-indices-of-deprivation2015 (Accessed 1st Aug 2018)

15 Perkins GD, Jacobs IG, Nadkarni VM, et al. Cardiac arrest and cardiopulmonary resuscitation outcome reports: update of the utstein resuscitation registry templates for out-of-hospital cardiac arrest: a statement for healthcare professionals from a task force of the international liaison committee on resuscitation (American Heart Association, European Resuscitation Council, Australian and New Zealand Council on Resuscitation, Heart and Stroke Foundation of Canada, InterAmerican Heart Foundation, Resuscitation Council of Southern Africa, Resuscitation council of asia); and the american heart association emergency cardiovascular care committee and the council on cardiopulmonary, critical care, perioperative and resuscitation. Resuscitation 2015;96:328-40.

16 Buuren S, Groothuis-Oudshoorn K. Multivariate imputation by chained equations in $r$. J Stat Softw 2011:45.

17 Barnard E, Yates D, Edwards A, et al. Reply to Letter: Mortality in traumatic cardiac arrest. Resuscitation 2017;113:e23.

18 Djarv T, Axelsson C, Herlitz J, et al. Traumatic cardiac arrest in Sweden 1990-2016 - a population-based national cohort study. Scand I Trauma Resusc Emerg Med 2018;26:30.

19 Smith JE, Rickard A, Wise D. Traumatic cardiac arrest. J R Soc Med 2015;108:11-16.

20 Goto Y, Funada A, Goto Y. Relationship between emergency medical services response time and bystander intervention in patients with out-of-hospital cardiac arrest. J Am Heart Assoc 2018;7:e007568.

21 Benger JR, Kirby K, Black S, et al. Effect of a strategy of a supraglottic airway device vs tracheal intubation during out-of-hospital cardiac arrest on functional outcome: the AIRWAYS-2 randomized clinical trial. JAMA 2018;320:779-91.

22 Dumas F, Bougouin W, Geri G, et al. Is epinephrine during cardiac arrest associated with worse outcomes in resuscitated patients? J Am Coll Cardiol 2014;64:2360-7.

23 Perkins GD, Ji C, Deakin CD, et al. A randomized trial of epinephrine in out-of-hospital cardiac arrest. N Engl J Med 2018;379:711-21.

24 Hamilton A, Steinmetz J, Wissenberg M, et al. Association between prehospital physician involvement and survival after out-of-hospital cardiac arrest: a danish nationwide observational study. Resuscitation 2016:108:95-101. 